\title{
An Information Resource Integration Platform for Community Service
}

\author{
Guoling Lao and Yanping Zhong \\ School of Information Management and Engineering, Shanghai University of Finance and \\ Economics, Shanghai 200433, P.R. China gllao@shufe.edu.cn
}

\begin{abstract}
E-commerce in community is a major application area of the EIS in community management industry. In this paper, by comparing three information integration structures of E-commerce in community, we arrive at a conclusion that application of E-commerce in community in China is still in its infancy of integration in single direction. In order to make workable integration in two-direction, then a website of $\mathrm{E}$-commerce service in community based on $\mathrm{i}$-bus is proposed. We make a two-layer information resource integration, whose first layer is information integration of E-commerce resources centered on residential requirements faced to community service and second is function integration of integrated management and E-commerce in community marked by distinctive community service, put into practice. In the end, we take the project of East Community Information Park (ECIP) to do a deep case study.
\end{abstract}

Keywords: Community, E-commerce, Enterprise information system (EIS), Integration

\section{INTRODUCTION}

The concept of Information resource integration is generated at the stage between development and system integration. It refers collecting, arranging and processing the information outside or inside the enterprises, so that the information are highly shared and integration to satisfy the need of system integration, process restructuring and outsider information integration [1]. This paper study E-business information resource integration platform of domestic community, combining the community service and information resource integration.

This paper is organized as follows: we analyze current situation of domestic community E-business information integration in Chapter 2; In Chapter 3, we propose community-oriented information resource integration platform based on i-bus and study the ECIP case in Chapter 4; and gave a conclusion in Chapter 5.

\section{THE CURRENT SITUATION OF DOMESTIC COMMUNITY E-BUSINESS INFORMATION RESOURCE INTEGRATION}

Review the study of information resource integration. These studies are mainly focus on the integration of enterprises information resource, most of which are

Please use the following format when citing this chapter:

Lao, G., Zhong, Y., 2007, in IFIP International Federation for Information Processing, Volume 255, Research and Practical Issues of Enterprise Information Systems II Volume 2, eds. L. Xu, Tjoa A., Chaudhry S. (Boston: Springer), pp. 1435-1440. 
technical study[2-4], but also include management study[5] on improving position of international service industry. Some studies about information resource integration facing community service emerge, including individuation integration [6], information integration of community library [7], information integration of Egovernment [8]. However, the theory about information resource integration from the aspect of community E-business is not mature. This paper studies the community Ebusiness service - oriented information resource integration, in connection with current problems of domestic community E-business.

Community in our country includes street community and subdistrict community. Form table 1, we can learn that community E-business does not realize double action integration, nor function integration.

Table 1. E-business Information Resource Integration Structure in Different Communities

\begin{tabular}{|c|c|c|c|c|c|}
\hline & \multirow{2}{*}{$\begin{array}{l}\text { Website } \\
\text { driver }\end{array}$} & \multicolumn{3}{|c|}{ E-business information integration structure } & \multirow{2}{*}{ explanation } \\
\hline & & left & center & right & \\
\hline $\begin{array}{l}\text { Street } \\
\text { community } \\
\text { E-business }\end{array}$ & goverment & goverment & $\begin{array}{l}\text { E-business } \\
\text { websites }\end{array}$ & 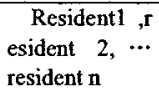 & $\begin{array}{l}\text { integrated the } \\
\text { residents part only }\end{array}$ \\
\hline \multirow[t]{2}{*}{$\begin{array}{l}\text { Subdistrict } \\
\text { community } \\
\text { E-business }\end{array}$} & $\begin{array}{l}\text { property } \\
\text { management } \\
\text { company }\end{array}$ & $\begin{array}{l}\text { Resident1 } \\
\text { resident } 2, \\
\text { resident } \mathbf{n}\end{array}$ & $\begin{array}{l}\text { E-business } \\
\text { websites }\end{array}$ & $\begin{array}{l}\text { resident } 1, \mathrm{re} \\
\text { sident } 2, \cdots \\
\text { resident } n\end{array}$ & $\begin{array}{l}\text { it is also just a } \\
\text { residents integration }\end{array}$ \\
\hline & $\begin{array}{l}\text { independe } \\
\text { nt investors }\end{array}$ & seller & $\begin{array}{l}\text { E-business } \\
\text { websites }\end{array}$ & $\begin{array}{l}\text { residentl, re } \\
\text { sident } 2, \quad \cdots \\
\text { resident n }\end{array}$ & $\begin{array}{l}\text { Through E- } \\
\text { business websites, } \\
\text { integrate the residents } \\
\text { part }\end{array}$ \\
\hline
\end{tabular}

\section{I-BUS-BASED COMMUNITY SERVICE-ORIENTED INTEGRATION PLATFORM FOR INFORMATION RESOURCES}

I-bus is a community information train, whose task is to integrate information and transfer them to the community residents. Judging from the structure, it contains two aspects: the web site and the consumer terminals. The web site here is neither a portal nor a professional website providing content. Instead, it is called knowledge service provide (KSP) website. Figure 1 is the structure map of $\mathrm{i}$-bus system. 


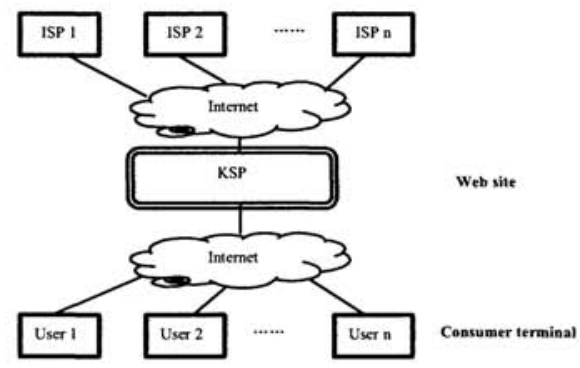

Figure 1. I-bus System Structure [9]

On the basis of i-bus structure, we propose a community service-oriented information resources integration platform as shown in Figure 2. The service centre platform is a KSP structured e-commerce web site. The second-level platform is actually an integration of integrated management and KSP. Residents here are the consumer terminal in i-bus structure.

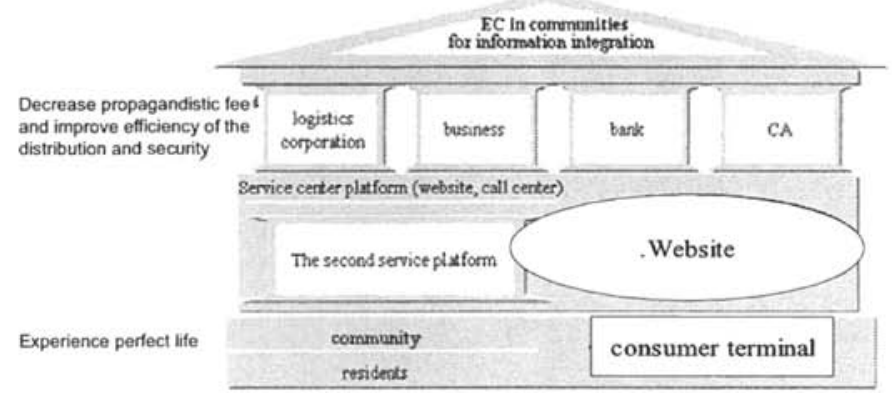

Figure 2. Community Service-oriented Information Resources Integration Platform [10]

Seen from figure 3, before integration, different suppliers provide different products or service, and residents had to contact each for different products or service. In general, the link of participants in the supply chain is quite complex. KSP, which is built through the service centre platform, integrates the business resources in front end of the supply chain, and the resident's information in back end. 

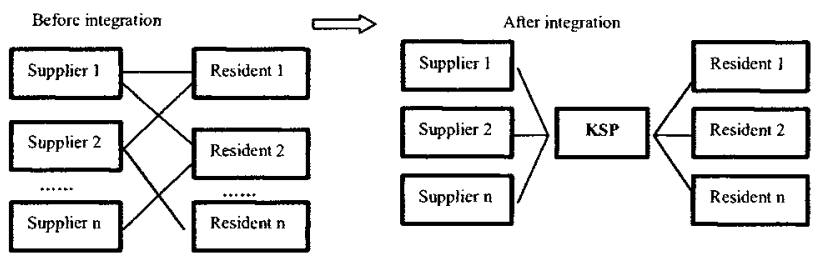

Figure 3. Information Resources Integration in the Supply Chain

KSP is the first level of i-bus-based community-oriented information resources integration platform, while integration management and KSP structured e-commerce is the second level. Before integration, the management of orders, payment, and distribution are conducted by the each supplier. After platform integration, KSP managers analyze residents' habit and preference according to the residents' information, to make it the criteria for the front-end supply chain businesses selection.

At the same time, in the process of e-commerce transaction, management of orders, payment and distribution are conducted by the KSP manager, and integrated with the function of e-commerce platform. In this process, information is updated all the time, making the KSP manager better understand residents' consuming preference, thereby forming a virtuous circle.

\section{CASE ANALYSIS ABOUT EAST COMMUNITY INFORMATION PARK (ECIP)}

ECIP (http://www.e-ommunity.com.cn/active/index.asp) is an independent thirdparty e-commerce service platform that firstly services the community residents and service enterprises. The analysis to east community information court facilitate people understand information resource integration platform based on the i-bus structure and community-oriented services.

\section{1) Background briefings about East Community Information Park}

In this context, ECIP project, according to the spirit of the document from the Shanghai Municipal Committee Propaganda department, the city civilization offices, the city Information Commission and the city Culture and Broadcast bureau, initiated in October 2003, built and operated by Shanghai East Digital Community Development Limited Corporation(http://www.e-community.com.cn/). The building idea was to establish 400 community information nodes around Shanghai and the new public cultural facilities and services platform based on information and community residents-oriented.

\section{2) Platform of East Community Information Park}

ECIP, as an open platform for the information center, integrated information of all types of enterprises in the supply chain, thus made members within the supply chain to share information. For the upstream supply chain businesses they can achieve accurate and timely supply chain information; for community residents, they can 
quickly achieve information, products and services what they need, through information platform filtered by the information court.

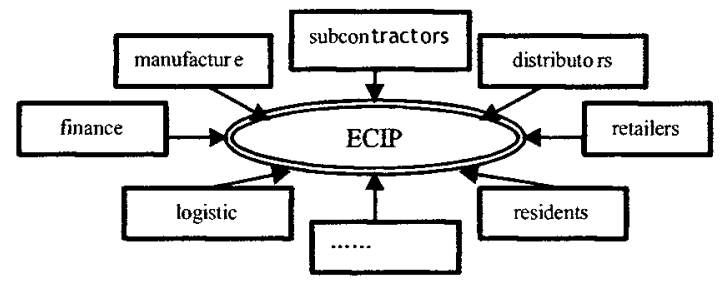

Figure 4. Information Resource Integration for East Community Information Park

Seen form Figure4, ECIP integrated the supply chain information as a Hub-andspoke, and each participant's internal information system has become the system's auxiliary. The service provided by ECIP included the public information, network supermarkets, e-commerce ticketing and so on, which have basically completed the first level integration of information resources based on i-bus structure and community-oriented services. Through unified order management, payment management and distribution management, ECIP basically completed the second level integration of integrating management and platform. In order management, information of orders will be sent to the corresponding businesses and ECIP marshaled the orders. In Payment management, ECIP cooperated with the banks, POS manufacturers, granted summary POS equipment to community residents. Through the integrated payment systems connected with bank systems, community residents can not only pay on computer through the online payments system, but also directly consume swiping cards through the family POS, even directly go to the service networks of ECIP for cashing. In distribution management, ECIP established service stations, formed the regional logistics network, and achieved a unified distribution for whole community.

\section{CONCLUSIONS}

By comparison the information integrating of street-based e-business to community-based e-business, we know that, in essence, e-business faced to residents is still in its monomial integrating phase in China. This paper puts forward an information integrating platform based on i-bus that faced to service the community. Then we take ECIP for example; implement the practical analysis of the information resource integration that is i-bus based structure and faced to service the community. Though ECIP is the nearly intact information resource integration platform and faced to service the community, its e-business function is poor. If the platform is just pay attention to the information display function, that maybe the inadequate information resource integration. So, in this aspect, we should pay more attention to the research and practice how to implement the e-business function. 


\section{REFERENCES}

1. J. Song, The Research of Generate Electricity Enterprises' Information Resource Integration in Our Country (Northern University of Electricity: Beijing, 2005).

2. A. Sheth and J. Larson, Federated Database System for Managing Distributed, Heterogeneous, and Autonomous Databases, ACM Computing Surveys. Volume 22, Number 3, (1991).

3. L. Hu and J. Wang, Technology of enterprise application integration based on web services, Computer Engineering and Design. Volume 26, Number 10, pp.2634-2638, (2005).

4. Y. Wang and Z. Hu, Integrating Technology of Information Resources Co-sharing under the Networked Environment, Information Science. Volume 22, Number 10, pp.12031205, (2004).

5. L.B. Randall, The Information Resource Management Concept Domain Measurement and Implementation Status, Ph.D Thesis, Auburn University (1993).

6. Q. Hu, Information Resource Integration Analysis in Individuation Service, Library Forum. Volume 25, Number 1, pp.122-125, (2005).

7. R.I. John, and G.J. Mooney, Fuzzy User Modeling for Information Retrieval on the World Wide Web, Knowledge and Information Systems. Volume 3, (2001).

8. J. Zhou and J. Gao, E-government Information Resources Integration Based on Knowledge Management, Information Science. Volume 24, Number 11, pp.1657-1661, (2006).

9. Y. Hu, F. Wang, and Y. Zhu, I-bus, a New Information Service Model for Neighborhood Community, Computer Engineering. Volume 27, Number 11, pp.80-83, (2001).

10. G. Lao and Y. Zhong, E-commerce Model in Community Based on Intelligent Building and Case Study, in Proc. of 2006 International Conference on Construction \& Real Estate Management (2006), pp.804-809. 